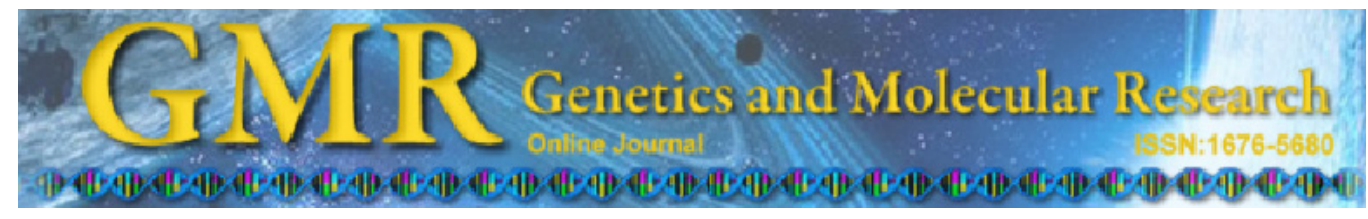

\title{
High segregation distortion in maize B73 $x$ teosinte crosses
}

\author{
G. Wang, Q.Q. He, Z.K. Xu and R.T. Song \\ Shanghai Key Laboratory of Bio-Energy Crop, School of Life Sciences, \\ Shanghai University, Shanghai, P.R. China \\ Corresponding author: R.T. Song \\ E-mail: rentaosong@staff.shu.edu.cn
}

Genet. Mol. Res. 11 (1): 693-706 (2012)

Received August 16, 2011

Accepted January 19, 2012

Published March 19, 2012

DOI http://dx.doi.org/10.4238/2012.March.19.3

\begin{abstract}
Two genetic linkage maps of cultivated maize inbred lines and teosinte species were constructed. One population comprised $81 \mathrm{~F}_{2}$ individuals derived from a cross between maize inbred line B73 and Zea mays ssp parviglumis, while the second consisted of 63 backcross individuals from a cross of maize inbred line B73 with Z. mays ssp diploperennis. In the $\mathrm{B} 73 \times$ Z . mays ssp parviglumis $\mathrm{F}_{2}$ population, 172 simple sequence repeat (SSR) markers were mapped to 10 chromosomes, which covered $2210.8 \mathrm{cM}$. In the $\mathrm{B} 73$ x Z. mays ssp diploperennis backcross population, 258 SSR markers were mapped to 10 chromosomes, covering $1357.7 \mathrm{cM}$. Comparison of the two maps revealed that the total map length of $Z$. mays ssp diploperennis covers $1357.7 \mathrm{cM}$, which is about $61.4 \%$ of that of $Z$. mays ssp parviglumis $(2210.8 \mathrm{cM})$. Extensive segregation distortion regions were found on chromosomes $1,2,3,5$, 6,7 , and 10 in the $\mathrm{B} 73 \times$ Z. mays ssp parviglumis $\mathrm{F}_{2}$ population and on chromosomes 1-5 and 8-10 in the $\mathrm{B} 73 \times \mathrm{Z}$. mays ssp parviglumis backcross population. Segregation distortion analysis confirmed that the segregation distortion ratio in the interspecific population $\mathrm{B} 73 \times \mathrm{X}$. mays ssp diploperennis was higher than in $\mathrm{B} 73 \times \mathrm{x}$. mays ssp parviglumis. We found that the recombination distances are highly variable in these genetic crosses between cultivated and wild species of maize.
\end{abstract}

Key words: Maize; Teosinte; Genetic linkage map; Shrinkage; Segregation distortion 


\section{INTRODUCTION}

Maize (Zea mays L.) is an important food and forage crop planted worldwide. Recently, maize breeding for high yield, robust quality, and disease resistance has become stagnant owing to the narrow genetic background of the maize germplasm. Therefore, exploring varieties of the germplasm for excellent potential gene sources is becoming more and more imperative.

Teosinte, the closest wild relative of maize, has been considered and used as a germplasm resource for maize improvement to provide disease resistance and various favorable agronomic traits (Cohen and Galinat, 1984). Because maize and teosinte have the same number of diploid chromosomes $(2 \mathrm{~N}=2 \mathrm{X}=20$; with the exception of Zea perennis, a tetraploid perennial teosinte), the fertile $\mathrm{F}_{1}$ hybrids can be easily acquired by crossing maize and teosinte. The gene flow moves from teosinte to maize via introgressive hybridization. During the introgression, the chromosome fragment of teosinte introgresses into the maize chromosome through repeated backcrosses (BC). The objective of $\mathrm{BC}$ breeding is to increase the recipient genome content and decrease the donor genome content by repeated $\mathrm{BC}$ to the recipient line. Two problems come to light during this process: foreground and background selection. A series of theoretical and practical studies indicate that a molecular marker can resolve these problems. The linkage maps show the genetic linkage relationship among different molecular markers, and these markers can be used for genome-wide scanning. Combined with a physical map, molecular marker analysis can confirm that a chromosome fragment introgressed from donor to recipient. Genetic maps provide important information for detailed genetic analysis of qualitative and quantitative traits and have proven to be important tools for plant improvement (Doerge, 2002).

During linkage map construction, recombination frequency and segregation distortion are notable. Recombination frequency is a measure of genetic linkage and is used in the creation of a genetic linkage map. Recombination rates are different among different parent combinations. The map length of an interspecific hybrid has been recognized as being shorter than that of an intraspecific hybrid (Doebley and Stec, 1991, 1993). Variability in recombination rates in maize was first reported in 1918 by Bregger and later confirmed using molecular markers (Tulsieram et al., 1992). Segregation distortion was first reported in maize by Mangelsdorf and Jones (1926) based on a linkage between the gametophyte factor Ga1 and the $\mathrm{Su}$ allele for starchy endosperm. At present, segregation distortion has been reported in rice (Harushima et al., 1996; Xu et al., 1997; Matsushita et al., 2003), maize (Lu et al., 2002; Sibov et al., 2003; Yan et al., 2003), barley (Konishi et al., 1992), grain sorghum (Pereira et al., 1994), and tomato (Paterson et al., 1991), among other crops. Segregation distortion may be related to the genetic background of the biparents. The segregation distortion ratio in interspecific populations is confirmed to be higher than that in intraspecific populations, that is, segregation distortion is prone to occur in interspecific populations. Further studies on segregation distortion in plants will enhance our understanding of deviant gene segregation during the introgression of target genes from wild species to cultivars.

In this study, we constructed two genetic linkage maps of maize $x$ teosinte. One population comprised $81 \mathrm{~F}_{2}$ individuals of maize inbred line B73 $\mathrm{x}$ Z. mays ssp parviglumis, and the other consisted of $63 \mathrm{BC}$ individuals of $\mathrm{B} 73 \times \mathrm{Z}$. mays ssp diploperennis. The analysis of the genetic linkage maps provided potential clues about the recombination frequency and segregation distortion of different genetic background combinations of maize and teosinte. 


\section{MATERIAL AND METHODS}

\section{Material}

Maize inbred line B73 was used as the maize parental line for genetic population construction. Zea mays ssp parviglumis (PI 384061, abbreviated as parviglumis) and Z. mays ssp diploperennis (PI 441931, abbreviated as diploperennis) were used as teosinte lines. B73 and parviglumis were used to develop an $\mathrm{F}_{2}$ mapping population. The $\mathrm{F}_{1}$ was generated from the cross between $\mathrm{B} 73$ and diploperennis, and $\mathrm{F}_{1}$ plants were then used as female parents and B73 as the male parents in the genetic cross $\mathrm{B} 73 \mathrm{x}_{1}$, to generate the $\mathrm{BC}$ population. Zea mays ssp parviglumis and diploperennis were planted in the greenhouse of Shanghai University. B73, $\mathrm{F}_{2}$, and $\mathrm{BC}$ populations were planted in the spring of 2008 in the experimental field on the Shanghai University campus. Eighty-two $\mathrm{F}_{2}$ individuals and $63 \mathrm{BC}$ individuals were randomly selected as the mapping population.

The genomic DNA of the parents (B73, Z. mays ssp parviglumis, and Z. mays ssp diploperennis) and $81 \mathrm{~F}_{2}$ and $63 \mathrm{BC}$ progeny were extracted for simple sequence repeat (SSR) analysis using the cetyltrimethylammonium bromide method (Murray and Thompson, 1980).

\section{Analysis of SSR markers}

On the principle of bin site uniform distribution, SSR primers were selected from the maize genetics and genomics database (http://www.maizegdb.org) published by the University of Missouri and were synthesized by the Shanghai Sango Biological Engineering Technology \& Services Co., Ltd. The polymorphic primers between B73 and parviglumis were used to analyze the $\mathrm{F}_{2}$ population, and the polymorphic primers between $\mathrm{B} 73$ and diploperennis were used to analyze the $\mathrm{BC}$ population.

A polymerase chain reaction (PCR) system with a total volume of $10 \mu \mathrm{L}$ was made with the following: $20 \mathrm{ng}$ template DNA, $10 \mathrm{pM}$ each primer, $200 \mu \mathrm{M}$ dinucleotide triphosphates, $1 \mathrm{X}$ buffer, $1.6 \mathrm{mM} \mathrm{MgCl}$, and $0.5 \mathrm{U}$ Taq DNA polymerase. The PCR process included $5 \mathrm{~min}$ at $94^{\circ} \mathrm{C}$ followed by 30 cycles of $35 \mathrm{~s}$ at $94^{\circ} \mathrm{C}, 40 \mathrm{~s}$ at $56^{\circ} \mathrm{C}$, and $1 \mathrm{~min}$ at $72^{\circ} \mathrm{C}$, and a final extension for $5 \mathrm{~min}$ at $72^{\circ} \mathrm{C}$. The electrophoretic separation of the PCR products was carried out with $8 \%$ polyacrylamide gel and $1 \mathrm{X}$ Tris-borate-ethylenediaminetetraacetic acid electrophoretic buffer under the constant power of $80 \mathrm{~W}$ followed by ethidium bromide staining.

\section{Genotypic statistics}

Each locus of the $\mathrm{F}_{2}$ progeny samples had three banding patterns. The patterns from B73 and parviglumis were labeled 1 and 2, respectively, a heterozygous pattern was marked with 3 , and a deletion with 0 . Each locus of the $\mathrm{BC}$ progeny samples had two banding patterns. The patterns from B73 were labeled 1, the heterozygous pattern was labeled 3, and a deletion was marked with 0 .

\section{Linkage analysis}

A linkage analysis was made by using Mapmaker/EXP 3.0b (Lander et al., 1987) and 
setting threshold of $\log$ of odds (LOD) $\geq 4.0$, the recombinant rates were converted into map distances (cM) with the Kosambi function, and a linkage map was constructed using the mapping commands (Lander et al., 1987).

\section{SSR marker segregation analysis}

Segregation of each marker in the two populations was tested for goodness of fit to the expected 1:2:1 (B73 x Z. mays ssp parviglumis $\mathrm{F}_{2}$ population) and 1:1 (B73 x Z. mays ssp diploperennis $\mathrm{BC}$ population) Mendelian segregation ratios using the $\chi^{2}$ analysis.

\section{RESULTS AND DISCUSSION}

\section{Polymorphism analysis}

A total of 713 SSR makers were screened between B73 and parviglumis, resulting in $220(30.9 \%)$ polymorphic markers. The polymorphic markers were then applied to the $\mathrm{F}_{2}$ population analysis. A total of 320 polymorphic markers were identified from 873 tested SSR markers between B73 and diploperennis, and the polymorphic ratio was $36.6 \%$. These markers were used to analyze the BC population.

In this study, B73 and parviglumis are different subspecies of the Z. mays species; however, B73 and diploperennis are different species of the genus Zea. The SSR analysis showed that the polymorphic ratio between B73 and diploperennis was higher than that between B73 and parviglumis. The result implied that the sequence divergence between B73 and parviglumis was less than that of B73 and diploperennis. Accordingly, parviglumis is considered to be more closely related to maize than are other types of teosinte (Doebley et al., 1984) based on the relative genetic distances calculated from allozyme frequencies.

\section{Map construction}

According to the segregation data of the 220 polymorphic SSR markers, a genetic linkage map of B73 x parviglumis was constructed, which included 11 linkage groups (10 chromosomes) and 172 SSR markers and spanned $2210.8 \mathrm{cM}$ (Figure 1). The longest linkage group was $327.3 \mathrm{cM}$; the shortest was $76.1 \mathrm{cM}$. The average genetic distance between two neighboring loci was $12.8 \mathrm{cM}$, and the distribution of markers on the chromosomes was relatively even, without crowding in any region.

The 320 polymorphic markers were used for analyzing the BC population (B73 x diploperennis). In the segregation analysis among the individual plants, 258 markers were mapped into 10 linkage groups, which spanned $1357.7 \mathrm{cM}$ with an average genetic distance between neighboring markers of $5.3 \mathrm{cM}$ (Figure 2). The longest distance was $198.1 \mathrm{cM}$; the shortest was $76.1 \mathrm{cM}$. Notably, the genetic distance between adjacent markers was $0 \mathrm{cM}$ in some regions.

Molecular linkage maps have been constructed for some maize $\mathrm{x}$ teosinte crosses, including Z. mays ssp x parviglumis (Doebley and Stec, 1993; Lauter and Doebley, 2002; Briggs et al., 2007), Z. mays ssp x mexicana (Doebley and Stec, 1991), Z. mays ssp x huehuetenangensis (Mano et al., 2005a,b), Z. luxurians (Omori and Mano, 2007; Mano et al., 2008) 
and Z. mays ssp x nicaraguensis (Mano et al., 2007; Mano et al., 2009), and a diploperennis $\mathrm{x}$ parviglumis cross (Westerbergh and Doebley, 2002). These linkage maps were constructed with various molecular markers (such as restriction fragment length polymorphism, amplified fragment length polymorphism, SSR, single-nucleotide polymorphism, and indels) based on the genetic population ( $\mathrm{F}_{2}$ or $\mathrm{BC}$ mainly). Previously, two maps were constructed based on the population of Z. mays ssp x parviglumis (Doebley and Stec, 1993; Briggs et al., 2007), but no maps have been constructed based on the population of $Z$. mays ssp x diploperennis. The population size, number of markers, and average distance of adjacent markers of $\mathrm{B} 73 \mathrm{x}$ parviglumis are inferior to those of the W22 x parviglumis map constructed by Briggs et al. (2007); however, as a base map, the B73 x parviglumis map could resolve the genetic linkage relationship among markers. These markers can be used for genome-wide scanning during introgressive hybridization.
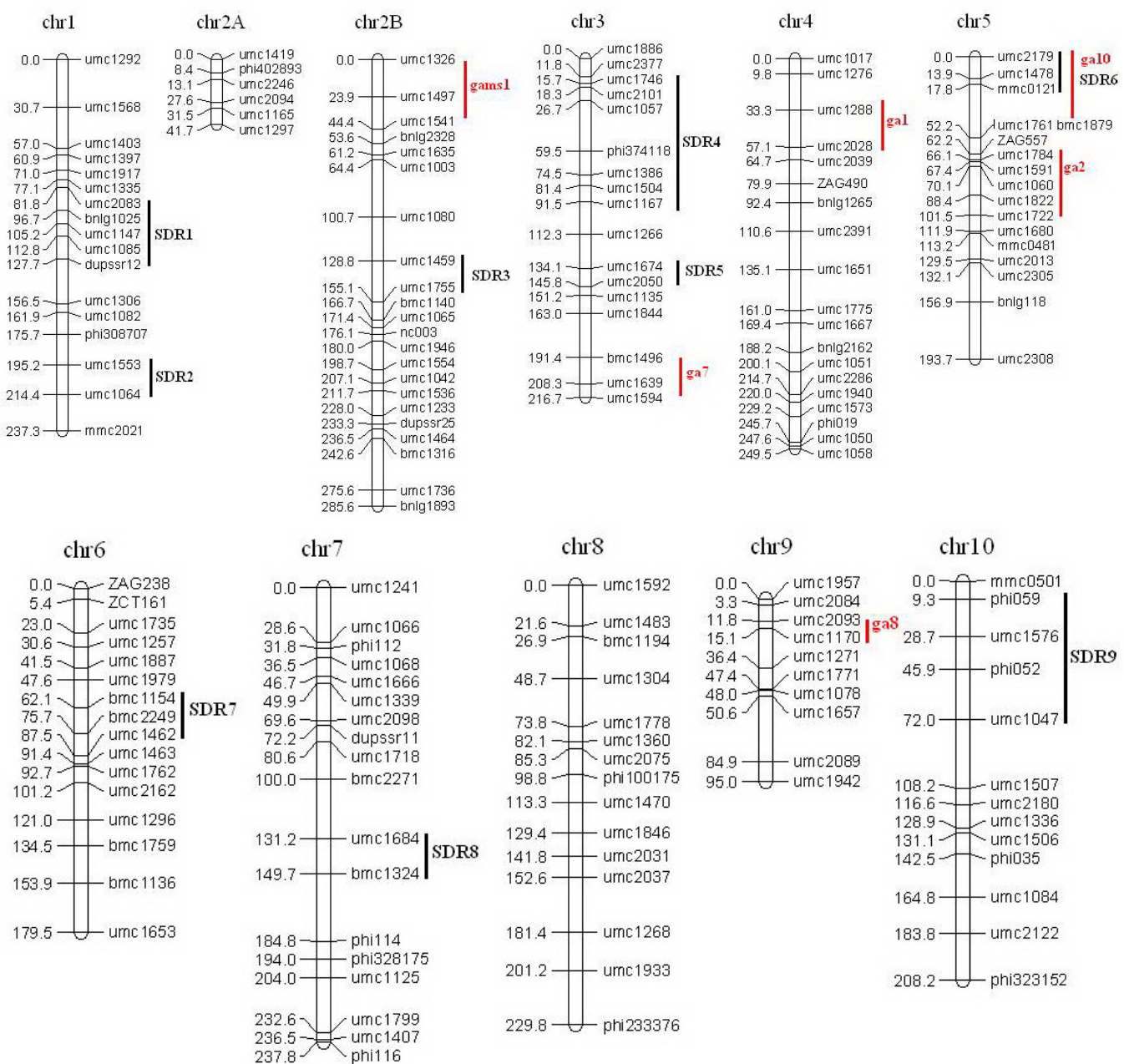

$\operatorname{chr} 9$

$\operatorname{chr} 10$

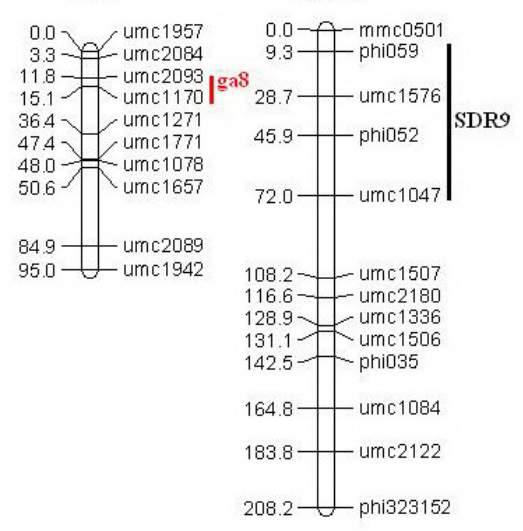

Figure 1. Genetic linkage map of B73 x Zea mays ssp parviglumis with SSR markers and the SDR distribution. $\mathrm{SDR}=$ Segregation distortion region; ga and gams = gametophytic factors. 

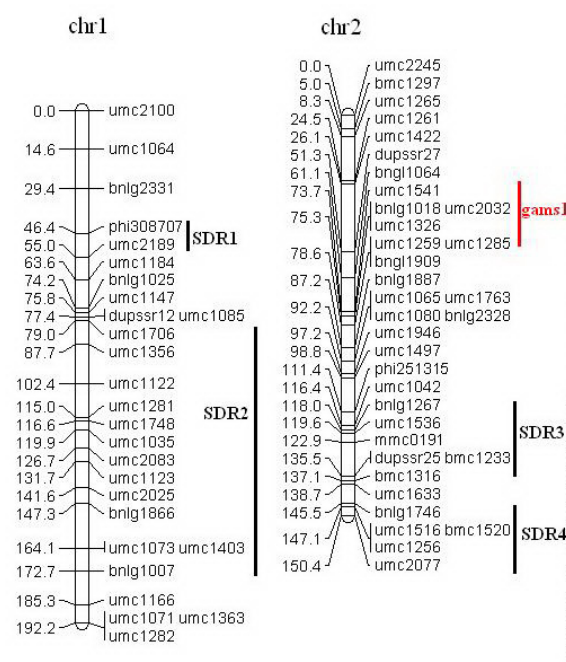

$\operatorname{chr} 4$

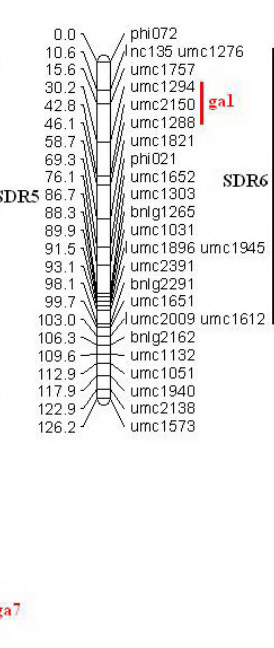

$\operatorname{chr} 5$

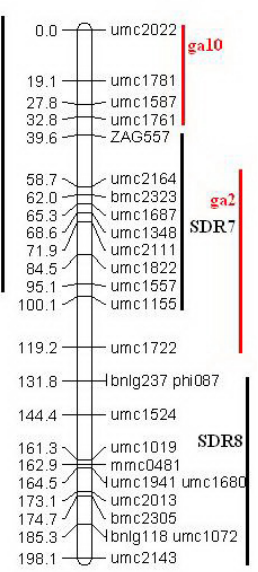

chr6

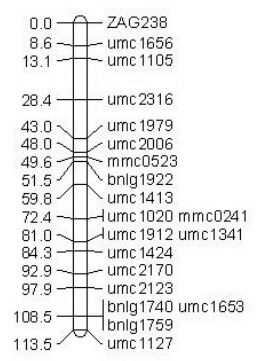

$\operatorname{chr} 7$

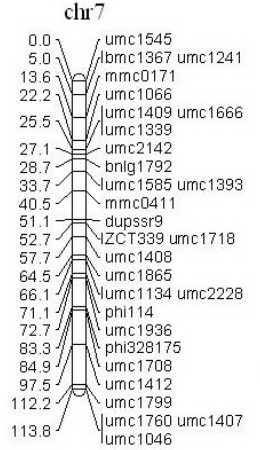

chr8

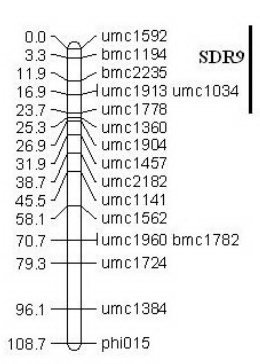

chr9

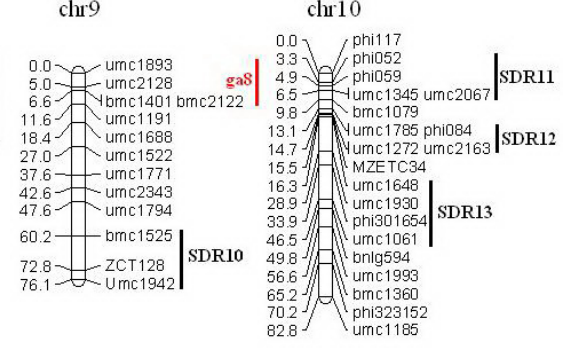

Figure 2. Genetic linkage map of B73 x Zea mays ssp diploperennis with SSR markers and the SDR distribution. $\mathrm{SDR}=$ Segregation distortion region; ga and gams $=$ gametophytic factors.

\section{Recombination frequency variability and recombination shrinkage}

Comparing the genetic length of each chromosome of our two linkage maps, we found that the genetic lengths of the chromosomes of B73 x parviglumis were longer than those of B73 $x$ diploperennis (except that of chromosome 5; Table 1). The length of chromosome 10 of the $\mathrm{B} 73 \mathrm{x}$ diploperennis linkage map was only $39.7 \%$ the length of chromosome 10 of B73 x parviglumis. The total map length of $\mathrm{B} 73 \mathrm{x}$ diploperennis covered $1357.7 \mathrm{cM}$, approximately $61.4 \%$ that of $\mathrm{B} 73 \mathrm{x}$ parviglumis $(2210.8 \mathrm{cM})$. The data suggested that the recombination distances were variable among different genetic background combinations. The genetic distances of all adjacent common markers of the B73 $\mathrm{x}$ diploperennis map were shorter than those of the B73 x parviglumis map. Compared with those of B73 x parviglumis, the genetic distances of bnlg1025-umc1147, umc1147-umc1085, umc1085-dupssr12, umc2025-umc1135, umc2305bnlg118, and umc1778-umc1360 of B73 x diploperennis were shrunken dramatically (Table 
2). When we compared the B73 $\mathrm{x}$ diploperennis map with the SSR map of intermated B73 $\mathrm{x}$ Mo17 (IBM) population (www.maizegdb.org), we found that the recombination shrinkage in the B73 $\mathrm{x}$ diploperennis map was ubiquitous. For example, the genetic distances of all adjacent common markers, such as umc1386-umc1773, umc2050-umc1135, umc1135-umc1767, umc1767-umc1489, and umc2152-umc1641 on chromosome 3 were shrunken (Table 3 ). The phenomenon of recombination shrinkage was obvious in the $\mathrm{B} 73 \mathrm{x}$ diploperennis linkage map.

\begin{tabular}{|c|c|c|c|c|c|c|c|c|c|c|c|c|}
\hline & & Chr. 1 & Chr. 2 & Chr. 3 & Chr. 4 & Chr. 5 & Chr. 6 & Chr. 7 & Chr. 8 & Chr. 9 & Chr. 10 & Total \\
\hline \multirow{2}{*}{ Total map length } & $\mathrm{B} 73 \times$ Z. mays ssp parviglumis & 237.3 & 327.3 & 216.7 & 249.5 & 193.7 & 179.5 & 237.8 & 229.8 & 95.0 & 208.2 & 2210.8 \\
\hline & $\mathrm{B} 73 \times$ Z. mays $\mathrm{ssp}$ diploperennis & 192.2 & 150.4 & 195.9 & 126.2 & 198.1 & 113.5 & 113.8 & 108.7 & 76.1 & 82.8 & 1357.7 \\
\hline \multirow[t]{2}{*}{ Average distance } & $\mathrm{B} 73 \times$ Z. mays ssp parviglumis & 13.8 & 11.7 & 12.7 & 12.5 & 11.3 & 10.9 & 13.8 & 15.3 & 9.8 & 16.8 & 12.8 \\
\hline & $\mathrm{B} 73 \times$ Z . mays ssp diploperennis & 7.1 & 4.3 & 4.4 & 4.8 & 7.6 & 5.7 & 3.9 & 6.4 & 5.9 & 4.1 & 5.3 \\
\hline
\end{tabular}

\begin{tabular}{|c|c|c|c|}
\hline \multirow[t]{2}{*}{ Marker } & \multicolumn{2}{|c|}{ Genetic distance $(\mathrm{cM})$} & \multirow[t]{2}{*}{ Chromosome } \\
\hline & B73 $\times$ Z. mays ssp parviglumis & B73 $\times$ Z. mays ssp diploperennis & \\
\hline bnlg1025-umc1147 & 8.5 & 1.6 & chr. 1 \\
\hline umc1147-umc1085 & 7.6 & 1.6 & chr. 1 \\
\hline umc1085-dupssr12 & 14.9 & 0.0 & chr. 1 \\
\hline umc1746-umc2101 & 2.6 & 0.0 & chr. 3 \\
\hline umc1386-umc1506 & 6.9 & 6.6 & chr. 3 \\
\hline umc2025-umc1135 & 5.4 & 0.0 & chr. 3 \\
\hline umc1135-umc1844 & 11.8 & 11.8 & chr. 3 \\
\hline umc1639-umc1594 & 8.4 & 7.0 & chr. 3 \\
\hline umc1761-ZAG557 & 10.0 & 6.8 & chr. 5 \\
\hline mmc0481-umc2305 & 1.3 & 1.6 & chr. 5 \\
\hline umc2305-bnlg118 & 24.8 & 10.6 & chr. 5 \\
\hline umc1666-umc1339 & 3.2 & 0.0 & chr. 7 \\
\hline umc1799-umc1407 & 3.9 & 1.6 & chr. 7 \\
\hline umc1778-umc1360 & 8.3 & 1.6 & chr. 8 \\
\hline
\end{tabular}

Table 3. Genetic distances of adjacent common markers on chromosome 3 of $\mathrm{B} 73 \mathrm{x}$ Zea mays ssp diploperennis and SSR map of intermated B73 x Mo17 (IBM) population.

\begin{tabular}{lccccc}
\hline & umc1386-umc1773 & umc2050-umc1135 & umc1135-umc1767 & umc1767-umc1489 & umc2152-umc1641 \\
\hline B73 x Z. mays ssp diploperennis & $3.3 \mathrm{cM}$ & $0.0 \mathrm{cM}$ & $0.0 \mathrm{cM}$ & $6.8 \mathrm{cM}$ & $6.8 \mathrm{cM}$ \\
SSR IBM map & $6.8 \mathrm{cM}$ & $1.5 \mathrm{cM}$ & $1.4 \mathrm{cM}$ & $17.6 \mathrm{cM}$ & $15.2 \mathrm{cM}$ \\
\hline
\end{tabular}

Previous research has found that the recombination levels in maize-teosinte hybrids are equivalent to those in maize-maize hybrids, indicating that the maize and teosinte genomes are similar (Emerson and Beadle, 1932). Contrastingly, Coe et al. (1990) have confirmed that the recombination between adjacent molecular markers in a maize-teosinte $\mathrm{F}_{2}$ population often appears smaller than that between the same markers in a maize-maize $\mathrm{F}_{2}$ population. A reduction of map length has been previously recognized in interspecific or wide cross-hybridizations of plants, including maize-teosinte crosses (Doebley and Stec, 1991, 1993; Williams et al., 1995). Recombination frequencies were different among different parental combinations. 
It has been recognized that the map length of an interspecific hybrid is shorter than that of an intraspecific hybrid. In $Z$. mays maps, recombination decreases progressively in the following order: maize $\mathrm{x}$ maize $>$ maize $\mathrm{x} Z$. mays $\operatorname{ssp}$ parviglumis $>$ maize $\mathrm{x} Z$. mays $\mathrm{ssp}$ mexicana in the $\mathrm{F}_{2}$ generation (Doebley and Stec, 1991, 1993). Comparison of the two map lengths convinced us that the map length of an interspecific hybrid (B73 x diploperennis) is shorter than that of an intraspecific hybrid (B73 x parviglumis).

The maize mapping studies suggest that the recombination rate heterogeneity among genetic backgrounds is under polygenic control. A study by Tulsieram et al. (1992) suggested that cis-factors potentially influence recombination rates. The first explanation for recombination shrinkage was based on the assumption that base-sequence homology determines where crossing-over will occur (Borts and Haber, 1987). Based on the theory of homologous recombination, we can deduce that genetic crossovers are more likely to occur between sequenceidentical homologues in homozygous regions than between sequence-divergent strands in heterozygous regions (Williams et al., 1995). The analysis of the $a 1$ gene suggests that sequence divergence can convert both a transcribed gene hot spot and an untranscribed gene hot spot into average spots or cold spots (Yao and Schnable, 2005). Compared with that of the B73 x parviglumis linkage map, the map length of $\mathrm{B} 73 \mathrm{x}$ diploperennis is obviously shrunken. The greater sequence divergence uncovered through SSR analysis may be one reason for the recombination shrinkage in the B73 x diploperennis linkage map.

Earlier studies have proven that recombination shrinkage increases the quantity of DNA and number of genes transmitted as a unit, reducing the precision at which individual genes (or traits) can be selected for. Reduced recombination in such regions may contribute greatly to maintaining trait associations by "linkage drag" or "genetic hitchhiking" (Birky Jr. and Walsh, 1988). Linkage drag will be a barrier to using exotic maize germplasm in maize breeding programs. From this perspective, parviglumis is better than diploperennis as a donor in $\mathrm{BC}$ breeding of maize.

\section{Segregation distortion}

Forty-eight (21.8\%) of 220 SSR markers in the B73 x parviglumis map indicated distorted segregation (Table 4). Nine segregation distortion regions (SDRs) were identified, distributed on all seven chromosomes except chromosomes 4, 8, and 9 (Figure 2). In B73 x diploperennis, $144(45.0 \%)$ polymorphic SSR markers showed aberrant segregation ratios (Table 5). A total of $116(80.6 \%)$ markers were located in putative SDRs. Thirteen SDRs were identified, distributed on eight chromosomes of maize except chromosome 6 and 7. The SDRs were unevenly distributed over 10 chromosomes. Chromosomes 3, 4, 8, and 9 had one SDR. Chromosomes 1, 2, and 5 had two SDRs, and chromosome 10 had three SDRs. In a comparison of the two maps, SDR2, SDR3, SDR4, SDR5, and SDR9 of B73 x parviglumis overlapped with SDR1, SDR3, SDR5, SDR11, and SDR12 of B73 x diploperennis.

Segregation distortion has frequently been found during the construction of genetic linkage maps. Segregation distortion for molecular markers in populations derived from wide crosses involving crop plants and their wild relatives is a common phenomenon (Doebley and Stec, 1991; Harushima et al., 1996). In tomato, Paterson et al. (1991) reported that 48 of 70 $(68 \%)$ markers at 21 distinct regions had distorted ratios in a cross with a related wild species. In rice, Xu et al. (1997) found chromosomal regions associated with marker-segregation distortion in six segregating populations. Bonierbale et al. (1988) has reported segregation distortion 
for eight regions in a cross between potato and a related species. In maize, Wendel et al. (1987) have observed that 11 of $17(65 \%)$ segregating allozyme loci showed significant segregation distortion in an $\mathrm{F}_{2}$ population. Gardiner et al. (1993) detected chromosomal regions associated with segregation distortion on chromosomes 1, 2, 3, and 5. In 2002, Lu et al. detected a total of 18 regions associated with segregation distortion on all of 10 maize chromosomes. In this study, 8 and 13 SDRs were detected in the B73 x parviglumis and B73 $\mathrm{x}$ diploperennis linkage maps, respectively. The B73 x diploperennis linkage map displayed more SDRs and SDR markers than the B73 x parviglumis map did. Population type (BC) and size (63 individuals) of the B73 $\mathrm{x}$ diploperennis map explain the higher segregation distortion. In addition, the result shows indirectly that segregation distortion is prone to happen in interspecific populations.

Table 4. Chi-square test for segregation distortion of markers in $\mathrm{B} 73 \mathrm{x}$ Zea mays ssp parviglumis $\mathrm{F}_{2}$ population.

\begin{tabular}{|c|c|c|c|c|c|c|c|}
\hline \multirow[t]{2}{*}{ Marker } & \multirow[t]{2}{*}{ Chromosome bin } & \multicolumn{4}{|c|}{ Genotype } & \multirow[t]{2}{*}{ P value } & \multirow[t]{2}{*}{ Chromosome location $(\mathrm{Y} / \mathrm{N})$} \\
\hline & & B73 & parviglumis & Heterozygote & Deletion & & \\
\hline Umc2083 & $1.05-1.06$ & 15 & 14 & 52 & 0 & 0.0377 & $\mathrm{Y}$ \\
\hline Umc1988 & 1.06 & 15 & 14 & 52 & 0 & 0.0337 & $\mathrm{~N}$ \\
\hline Bnlg1025 & 1.07 & 13 & 13 & 55 & 0 & 0.0056 & $\mathrm{Y}$ \\
\hline Dupssr12 & 1.08 & 10 & 13 & 58 & 0 & $* *$ & Y \\
\hline Umc1085 & 1.08 & 10 & 25 & 46 & 0 & 0.0295 & $\mathrm{Y}$ \\
\hline Umc2047 & 1.09 & 68 & 0 & 13 & 0 & $* *$ & $\mathrm{~N}$ \\
\hline Umc1064 & 1.11 & 29 & 13 & 39 & 0 & 0.0401 & $\mathrm{Y}$ \\
\hline Umc1553 & 1.11 & 30 & 16 & 35 & 0 & 0.0421 & $\mathrm{Y}$ \\
\hline Umc1459 & 2.05 & 12 & 13 & 55 & 1 & 0.0038 & $\mathrm{Y}$ \\
\hline Umc1755 & 2.06 & 34 & 17 & 30 & 0 & 0.0019 & $\mathrm{Y}$ \\
\hline Umc2129 & 2.07 & 38 & 0 & 43 & 0 & $* *$ & $\mathrm{~N}$ \\
\hline Umc1633 & 2.08 & 66 & 0 & 11 & 4 & $* *$ & $\mathrm{~N}$ \\
\hline umc1746 & 3.00 & 22 & 0 & 59 & 0 & $* *$ & $\mathrm{~N}$ \\
\hline Umc2101 & 3.00 & 28 & 12 & 41 & 0 & 0.0421 & $\mathrm{Y}$ \\
\hline Umc1746 & 3.00 & 29 & 13 & 39 & 0 & 0.0401 & Y \\
\hline Umc1886 & 3.01 & 21 & 9 & 51 & 0 & 0.0111 & $\mathrm{Y}$ \\
\hline Umc1057 & 3.02 & 29 & 10 & 42 & 0 & 0.0110 & $\mathrm{Y}$ \\
\hline phi374118 & 3.02 & 29 & 0 & 52 & 0 & $* *$ & $\mathrm{Y}$ \\
\hline Umc1386 & 3.04 & 24 & 0 & 56 & 1 & $* *$ & $\mathrm{Y}$ \\
\hline Umc1504 & 3.04 & 24 & 6 & 51 & 0 & 0.0021 & Y \\
\hline Umc1167 & 3.05 & 26 & 10 & 45 & 0 & 0.0257 & Y \\
\hline Umc1674 & 3.06 & 31 & 16 & 34 & 0 & 0.0219 & Y \\
\hline Umc2050 & 3.07 & 26 & 11 & 44 & 0 & 0.0459 & $\mathrm{Y}$ \\
\hline Umc2152 & 3.09 & 28 & 9 & 39 & 5 & 0.0097 & $\mathrm{~N}$ \\
\hline Umc1329 & 4.06 & 34 & 18 & 29 & 0 & 0.0016 & $\mathrm{~N}$ \\
\hline Umc2139 & 4.09 & 67 & 0 & 14 & 0 & $* *$ & $\mathrm{~N}$ \\
\hline Umc2179 & 5.01 & 13 & 16 & 52 & 0 & 0.0342 & $\mathrm{Y}$ \\
\hline Mmc0121 & $5.01-5.02$ & 15 & 7 & 59 & 0 & $* *$ & $\mathrm{Y}$ \\
\hline Umc1462 & 6.05 & 21 & 11 & 49 & 0 & 0.0489 & $\mathrm{Y}$ \\
\hline Bmc1154 & 6.05 & 26 & 11 & 44 & 0 & 0.0459 & Y \\
\hline Umc2170 & 6.06 & 64 & 0 & 16 & 1 & $* *$ & $\mathrm{~N}$ \\
\hline Umc1545 & 7.00 & 71 & 0 & 10 & 0 & $* *$ & $\mathrm{~N}$ \\
\hline Umc1068 & 7.02 & 15 & 13 & 53 & 0 & 0.0201 & $\mathrm{Y}$ \\
\hline Umc1684 & 7.03 & 32 & 7 & 42 & 0 & $* *$ & $\mathrm{Y}$ \\
\hline Umc1324 & 7.03 & 44 & 0 & 37 & 0 & $* *$ & Y \\
\hline phi420701 & 8.00 & 39 & 0 & 42 & 0 & $* *$ & $\mathrm{~N}$ \\
\hline phi100175 & 8.03 & 21 & 11 & 49 & 0 & 0.0489 & $\mathrm{Y}$ \\
\hline Umc1268 & 8.07 & 30 & 27 & 24 & 0 & 0.0011 & $\mathrm{Y}$ \\
\hline phi233376 & 8.09 & 19 & 10 & 52 & 0 & 0.014 & $\mathrm{Y}$ \\
\hline Umc1596 & 9.01 & 67 & 0 & 14 & 0 & $* *$ & $\mathrm{~N}$ \\
\hline phi052 & 10.02 & 27 & 0 & 54 & 0 & $* *$ & $\mathrm{Y}$ \\
\hline Umc1576 & 10.02 & 27 & 9 & 45 & 0 & 0.0111 & $\mathrm{Y}$ \\
\hline phi059 & 10.02 & 15 & 8 & 56 & 2 & $* *$ & $\mathrm{Y}$ \\
\hline Umc1047 & 10.03 & 35 & 0 & 46 & 0 & $* *$ & $\mathrm{Y}$ \\
\hline phi323152 & 10.05 & 23 & 8 & 50 & 0 & 0.0067 & $\mathrm{Y}$ \\
\hline phi035 & 10.06 & 18 & 0 & 63 & 0 & $* *$ & $\mathrm{Y}$ \\
\hline
\end{tabular}

$* * \mathrm{P}<0.001$ 
Table 5. Chi-square test for segregation distortion of markers in B73 x Zea mays ssp diploperennis $\mathrm{BC}$ population.

\begin{tabular}{|c|c|c|c|c|c|c|}
\hline \multirow[t]{2}{*}{ Marker } & \multirow[t]{2}{*}{ Chromosome bin } & \multicolumn{3}{|c|}{ Genotype } & \multirow[t]{2}{*}{$P$ value } & \multirow[t]{2}{*}{ Chromosome location $(\mathrm{Y} / \mathrm{N})$} \\
\hline & & B73 & Heterozygote & Deletion & & \\
\hline Phi308707 & 1.10 & 41 & 22 & 0 & 0.016 & $\mathrm{Y}$ \\
\hline Umc2189 & 1.10 & 40 & 23 & 0 & 0.003 & $\mathrm{Y}$ \\
\hline Umc1147 & 1.07 & 40 & 23 & 0 & 0.032 & $\mathrm{Y}$ \\
\hline Umc1706 & 1.07 & 40 & 22 & 1 & 0.023 & $\mathrm{Y}$ \\
\hline Umc1356 & 1.07 & 40 & 21 & 2 & 0.016 & $\mathrm{Y}$ \\
\hline Umc1122 & $1.07 / 1.06$ & 45 & 17 & 1 & $* *$ & $\mathrm{Y}$ \\
\hline Umc1281 & 1.06 & 42 & 21 & 0 & 0.008 & $\mathrm{Y}$ \\
\hline Umc1748 & 1.06 & 43 & 20 & 0 & 0.003 & $\mathrm{Y}$ \\
\hline Umc1035 & 1.06 & 41 & 22 & 0 & 0.016 & $\mathrm{Y}$ \\
\hline Umc1123 & 1.06 & 42 & 21 & 0 & 0.008 & $\mathrm{Y}$ \\
\hline Umc2083 & $1.05-1.06$ & 43 & 20 & 0 & 0.003 & $\mathrm{Y}$ \\
\hline Umc2025 & 1.05 & 43 & 19 & 1 & 0.002 & $\mathrm{Y}$ \\
\hline Bnlg1866 & 1.03 & 45 & 18 & 0 & $* *$ & $\mathrm{Y}$ \\
\hline Umc1073 & 1.03 & 42 & 21 & 0 & 0.008 & $\mathrm{Y}$ \\
\hline Umc1403 & 1.03 & 42 & 21 & 0 & 0.008 & $\mathrm{Y}$ \\
\hline Bnlg1007 & 1.02 & 43 & 20 & 0 & 0.003 & $\mathrm{Y}$ \\
\hline Umc1071 & 1.01 & 40 & 23 & 0 & 0.032 & $\mathrm{Y}$ \\
\hline Umc1363 & 1.01 & 40 & 23 & 0 & 0.032 & $\mathrm{Y}$ \\
\hline Umc1282 & 1.01 & 40 & 23 & 0 & 0.032 & $\mathrm{Y}$ \\
\hline Bnlg1887 & 2.06 & 23 & 40 & 0 & 0.032 & $\mathrm{Y}$ \\
\hline Bnlg1267 & $2.07 / 2.08$ & 20 & 41 & 2 & 0.007 & $\mathrm{Y}$ \\
\hline Umc1536 & $2.07 / 2.08$ & 19 & 44 & 0 & 0.001 & $\mathrm{Y}$ \\
\hline mmc0191 & $2.07 / 2.08$ & 19 & 43 & 2 & 0.002 & $\mathrm{Y}$ \\
\hline dupssr25 & 2.08 & 12 & 51 & 0 & $* *$ & $\mathrm{Y}$ \\
\hline Bmc1233 & 2.08 & 12 & 51 & 0 & $* *$ & $\mathrm{Y}$ \\
\hline Bmc1316 & 2.08 & 11 & 52 & 0 & $* *$ & $\mathrm{Y}$ \\
\hline Bnlg1746 & 2.08 & 6 & 56 & 1 & $* *$ & $\mathrm{Y}$ \\
\hline Umc1516 & 2.08 & 5 & 58 & 0 & $* *$ & $\mathrm{Y}$ \\
\hline Bmc1520 & 2.09 & 5 & 58 & 0 & $* *$ & $\mathrm{Y}$ \\
\hline Umc1256 & 2.09 & 5 & 58 & 0 & $* *$ & $\mathrm{Y}$ \\
\hline Umc2077 & 2.09 & 5 & 58 & 0 & $* *$ & $\mathrm{Y}$ \\
\hline Umc1394 & 3.01 & 40 & 23 & 0 & 0.032 & $\mathrm{Y}$ \\
\hline Umc1814 & 3.02 & 43 & 20 & 0 & 0.003 & $\mathrm{Y}$ \\
\hline Bmc1144 & 3.02 & 44 & 19 & 0 & 0.001 & $\mathrm{Y}$ \\
\hline Bmc1325 & $3.02 / 3.03$ & 44 & 19 & 0 & 0.001 & $\mathrm{Y}$ \\
\hline Bmc1523 & $3.02 / 3.03$ & 44 & 19 & 0 & 0.001 & $\mathrm{Y}$ \\
\hline Bmc1647 & 3.02 & 44 & 15 & 1 & $* *$ & $\mathrm{Y}$ \\
\hline Umc2369 & 3.03 & 44 & 16 & 3 & $* *$ & $\mathrm{Y}$ \\
\hline Umc1965 & 3.04 & 41 & 22 & 0 & 0.016 & $\mathrm{Y}$ \\
\hline Umc1351 & 3.04 & 42 & 20 & 1 & 0.005 & $\mathrm{Y}$ \\
\hline Umc1425 & 3.04 & 42 & 20 & 1 & 0.005 & $\mathrm{Y}$ \\
\hline Umc2033 & 3.04 & 44 & 19 & 0 & 0.001 & $\mathrm{Y}$ \\
\hline Bmc1452 & 3.04 & 40 & 23 & 0 & 0.032 & $\mathrm{Y}$ \\
\hline Umc2259 & 3.03 & 45 & 18 & 0 & $* *$ & $\mathrm{Y}$ \\
\hline Umc2258 & 3.03 & 45 & 18 & 0 & $* *$ & $\mathrm{Y}$ \\
\hline phi036 & 3.04 & 43 & 20 & 0 & 0.003 & $\mathrm{Y}$ \\
\hline Umc1729 & 3.04 & 43 & 20 & 0 & 0.003 & $\mathrm{Y}$ \\
\hline Umc1386 & 3.04 & 43 & 15 & 5 & $* *$ & $\mathrm{Y}$ \\
\hline Umc1773 & 3.04 & 44 & 19 & 0 & 0.001 & $\mathrm{Y}$ \\
\hline Umc1504 & 3.04 & 44 & 19 & 0 & 0.001 & $\mathrm{Y}$ \\
\hline Umc1350 & 6.07 & 45 & 18 & 0 & $* *$ & $\mathrm{Y}$ \\
\hline Umc1174 & 3.05 & 45 & 18 & 0 & $* *$ & $\mathrm{Y}$ \\
\hline Umc1300 & 3.05 & 45 & 18 & 0 & $* *$ & $\mathrm{Y}$ \\
\hline Umc1158 & 3.05 & 45 & 18 & 0 & $* *$ & $\mathrm{Y}$ \\
\hline Bnlg2241 & 3.06 & 44 & 19 & 0 & 0.001 & $\mathrm{Y}$ \\
\hline Bnlg1063 & 3.06 & 41 & 22 & 0 & 0.016 & $\mathrm{Y}$ \\
\hline Bmc1350 & $3.08 / 8.07$ & 42 & 21 & 0 & 0.008 & $\mathrm{Y}$ \\
\hline Umc1644 & 3.06 & 39 & 23 & 1 & 0.043 & $\mathrm{Y}$ \\
\hline nc135 & 4.01 & 44 & 19 & 0 & 0.001 & $\mathrm{Y}$ \\
\hline Umc1276 & 4.01 & 44 & 19 & 0 & 0.001 & $\mathrm{Y}$ \\
\hline Umc1757 & 4.01 & 45 & 18 & 0 & $* *$ & $\mathrm{Y}$ \\
\hline
\end{tabular}

Continued on next page 
Table 5. Continued.

\begin{tabular}{|c|c|c|c|c|c|c|}
\hline \multirow[t]{2}{*}{ Marker } & \multirow[t]{2}{*}{ Chromosome bin } & \multicolumn{3}{|c|}{ Genotype } & \multirow[t]{2}{*}{$P$ value } & \multirow[t]{2}{*}{ Chromosome location $(\mathrm{Y} / \mathrm{N})$} \\
\hline & & $\mathrm{B} 73$ & Heterozygote & Deletion & & \\
\hline Umc1294 & 4.02 & 49 & 14 & 0 & $* *$ & $\mathrm{Y}$ \\
\hline Umc 2150 & 4.02 & 46 & 17 & 0 & $* *$ & $\mathrm{Y}$ \\
\hline Umc1288 & 4.02 & 44 & 19 & 0 & 0.001 & $\mathrm{Y}$ \\
\hline Umc1821 & $4.03 / 4.04$ & 40 & 22 & 1 & 0.023 & $\mathrm{Y}$ \\
\hline phi021 & 4.03 & 43 & 18 & 2 & 0.001 & $\mathrm{Y}$ \\
\hline Umc1652 & 4.04 & 43 & 20 & 0 & 0.003 & $\mathrm{Y}$ \\
\hline Umc 1303 & 4.05 & 45 & 18 & 0 & $* *$ & Y \\
\hline Bnlg1265 & 4.05 & 44 & 19 & 0 & 0.001 & $\mathrm{Y}$ \\
\hline Umc1031 & 4.05 & 45 & 16 & 2 & $* *$ & $\mathrm{Y}$ \\
\hline Umc1896 & 4.05 & 46 & 17 & 0 & $* *$ & $\mathrm{Y}$ \\
\hline Umc1945 & 4.06 & 46 & 17 & 0 & $* *$ & $\mathrm{Y}$ \\
\hline Umc2391 & 4.06 & 45 & 18 & 0 & $* *$ & $\mathrm{Y}$ \\
\hline Bnlg2291 & 4.06 & 42 & 20 & 1 & 0.005 & $\mathrm{Y}$ \\
\hline Umc1651 & 4.07 & 43 & 18 & 2 & 0.001 & $\mathrm{Y}$ \\
\hline Umc2009 & 4.08 & 41 & $\begin{array}{l}10 \\
22\end{array}$ & 0 & 0.016 & $\begin{array}{l}1 \\
Y\end{array}$ \\
\hline zag557 & $\begin{array}{l}4.00 \\
5.03\end{array}$ & 41 & 22 & 0 & 0.016 & $\begin{array}{l}1 \\
Y\end{array}$ \\
\hline Umc2164 & 5.05 & 43 & 19 & 1 & 0.002 & $\begin{array}{l}1 \\
Y\end{array}$ \\
\hline Bmc2323 & 5.04 & 43 & 20 & 0 & 0.003 & $\begin{array}{l}1 \\
Y\end{array}$ \\
\hline Umc1687 & $\begin{array}{l}.04 \\
5.05\end{array}$ & 43 & 20 & 0 & 0.003 & $\begin{array}{l}1 \\
Y\end{array}$ \\
\hline Umc1348 & 5.05 & 40 & 22 & 1 & 0.023 & $\begin{array}{l}1 \\
Y\end{array}$ \\
\hline Umc2111 & 5.05 & 41 & 20 & 2 & 0.007 & $\begin{array}{l}1 \\
Y\end{array}$ \\
\hline Umc1822 & 5.05 & 42 & 21 & 0 & 0.008 & Y \\
\hline Umc1557a & 5.03 & 40 & 23 & 0 & 0.032 & $\begin{array}{l}1 \\
Y\end{array}$ \\
\hline Umc1155 & 5.05 & 43 & 19 & 1 & 0.002 & $\begin{array}{l}1 \\
Y\end{array}$ \\
\hline Bnlg1237 & $5.05 / 5.06$ & 42 & 21 & 0 & 0.008 & $\mathrm{Y}$ \\
\hline phi087 & $\begin{array}{c}5.05 / 5.00 \\
5.06\end{array}$ & $\begin{array}{l}42 \\
42\end{array}$ & $\begin{array}{l}21 \\
21\end{array}$ & 0 & $\begin{array}{l}0.000 \\
0.008\end{array}$ & $\begin{array}{l}\mathrm{Y} \\
\mathrm{Y}\end{array}$ \\
\hline Umc1524 & $\begin{array}{l}5.00 \\
5.06\end{array}$ & $\begin{array}{l}42 \\
48\end{array}$ & $\begin{array}{l}21 \\
15\end{array}$ & 0 & $\begin{array}{l}0.000 \\
* *\end{array}$ & $\begin{array}{l}\mathrm{Y} \\
\mathrm{Y}\end{array}$ \\
\hline Umc1019 & $\begin{array}{l}5.00 \\
5.06\end{array}$ & $\begin{array}{l}40 \\
40\end{array}$ & 23 & 0 & 0.032 & $\begin{array}{l}\mathrm{Y} \\
\mathrm{Y}\end{array}$ \\
\hline $\mathrm{mmc} 0481$ & $\begin{array}{l}5.00 \\
5.06\end{array}$ & $\begin{array}{l}40 \\
41\end{array}$ & $\begin{array}{l}25 \\
22\end{array}$ & 0 & 0.016 & $\begin{array}{l}1 \\
Y\end{array}$ \\
\hline Umc1941 & $\begin{array}{l}5.00 \\
5.06\end{array}$ & $\begin{array}{l}41 \\
42\end{array}$ & 21 & 0 & $\begin{array}{l}0.010 \\
0.008\end{array}$ & $\begin{array}{l}\mathrm{Y} \\
\mathrm{Y}\end{array}$ \\
\hline Umc1680 & 5.06 & 42 & 21 & 0 & 0.008 & $\begin{array}{l}1 \\
Y\end{array}$ \\
\hline Umc2013 & 5.07 & 45 & $\begin{array}{l}21 \\
18\end{array}$ & 0 & $\begin{array}{l}0.000 \\
* *\end{array}$ & $\begin{array}{l}1 \\
Y\end{array}$ \\
\hline Bmc2305 & 5.07 & 46 & $\begin{array}{l}10 \\
17\end{array}$ & 0 & $* *$ & $\begin{array}{l}1 \\
Y\end{array}$ \\
\hline Bnlg118 & 5.07 & $\begin{array}{l}40 \\
27\end{array}$ & 35 & 1 & 0.001 & $\begin{array}{l}1 \\
Y\end{array}$ \\
\hline Umc1072 & 5.07 & 44 & 19 & 0 & 0.001 & $\begin{array}{l}1 \\
Y\end{array}$ \\
\hline Umc2143 & 5.08 & 43 & 19 & 1 & 0.002 & $\begin{array}{l}1 \\
Y\end{array}$ \\
\hline Umc1592 & $\begin{array}{l}5.00 \\
8.01\end{array}$ & 42 & 21 & $\begin{array}{l}1 \\
0\end{array}$ & 0.008 & $\begin{array}{l}1 \\
Y\end{array}$ \\
\hline Bmc1194 & $\begin{array}{c}0.01 \\
8.01 / 8.02\end{array}$ & $\begin{array}{l}42 \\
42\end{array}$ & $\begin{array}{l}21 \\
21\end{array}$ & 0 & $\begin{array}{l}0.000 \\
0.008\end{array}$ & $\begin{array}{l}\mathrm{Y} \\
\mathrm{Y}\end{array}$ \\
\hline Bmc2235 & $\begin{array}{c}0.01 / 0.02 \\
8.02\end{array}$ & 41 & $\begin{array}{l}21 \\
22\end{array}$ & 0 & $\begin{array}{l}0.000 \\
0.016\end{array}$ & $\begin{array}{l}\mathrm{Y} \\
\mathrm{Y}\end{array}$ \\
\hline Umc1913 & $\begin{array}{l}0.02 \\
8.02\end{array}$ & $\begin{array}{l}41 \\
40\end{array}$ & 23 & 0 & 0.032 & $\begin{array}{l}\mathrm{Y} \\
\mathrm{Y}\end{array}$ \\
\hline Umc1034 & $\begin{array}{c}0.02 \\
8.02 / 8.03\end{array}$ & 40 & 23 & 0 & 0.032 & $\begin{array}{l}1 \\
Y\end{array}$ \\
\hline Umc1778 & $\begin{array}{c}0.0270 .03 \\
8.03\end{array}$ & 40 & 23 & 0 & 0.032 & $\begin{array}{l}1 \\
Y\end{array}$ \\
\hline Umc1904 & $\begin{array}{l}0.03 \\
8.03\end{array}$ & 40 & 23 & 0 & 0.032 & $\begin{array}{l}1 \\
Y\end{array}$ \\
\hline Umc1562 & $\begin{array}{l}0.05 \\
8.05\end{array}$ & 40 & 23 & 0 & 0.032 & $\begin{array}{l}1 \\
Y\end{array}$ \\
\hline Umc1724 & $\begin{array}{l}0.03 \\
8.06\end{array}$ & 42 & 21 & 0 & 0.008 & $\begin{array}{l}1 \\
Y\end{array}$ \\
\hline Bmc1525 & $\begin{array}{l}0.00 \\
9.07\end{array}$ & $\begin{array}{l}42 \\
39\end{array}$ & 23 & 1 & 0.043 & $\begin{array}{l}1 \\
Y\end{array}$ \\
\hline zct128 & 9.07 & 40 & 23 & $\begin{array}{l}1 \\
0\end{array}$ & 0.032 & $\begin{array}{l}1 \\
Y\end{array}$ \\
\hline Umc1942 & 9.07 & 40 & 23 & 0 & 0.032 & $\begin{array}{l}1 \\
Y\end{array}$ \\
\hline phi052 & 10.02 & $\begin{array}{l}40 \\
39\end{array}$ & 23 & 1 & 0.043 & $\begin{array}{l}1 \\
Y\end{array}$ \\
\hline phi059 & $\begin{array}{l}10.02 \\
10.02\end{array}$ & 40 & 23 & $\begin{array}{l}1 \\
0\end{array}$ & 0.032 & $\begin{array}{l}1 \\
Y\end{array}$ \\
\hline Umc1345 & 10.03 & 41 & 22 & 0 & 0.016 & $\begin{array}{l}1 \\
Y\end{array}$ \\
\hline Umc2067 & 10.03 & 41 & 22 & 0 & 0.016 & $\begin{array}{l}1 \\
Y\end{array}$ \\
\hline Umc1785 & 10.03 & $\begin{array}{l}41 \\
39\end{array}$ & 22 & 2 & 0.031 & $\begin{array}{l}1 \\
Y\end{array}$ \\
\hline phi084 & 10.04 & 41 & 22 & 0 & 0.016 & $\begin{array}{l}1 \\
Y\end{array}$ \\
\hline Umc1272 & $\begin{array}{l}10.04 \\
10.04\end{array}$ & 42 & 21 & 0 & 0.008 & $\begin{array}{l}1 \\
Y\end{array}$ \\
\hline Umc2163 & 10.04 & 42 & 21 & 0 & $\begin{array}{l}0.000 \\
0.008\end{array}$ & $\begin{array}{l}1 \\
Y\end{array}$ \\
\hline Umc1648 & 10.04 & 43 & 20 & 0 & 0.003 & $\begin{array}{l}1 \\
Y\end{array}$ \\
\hline Umc1930 & 10.04 & 42 & 21 & 0 & 0.008 & $\begin{array}{l}1 \\
Y\end{array}$ \\
\hline phi301654 & 10.04 & 43 & 20 & 0 & 0.003 & $\mathrm{Y}$ \\
\hline Umc1061 & 10.06 & 40 & 23 & 0 & 0.032 & $\mathrm{Y}$ \\
\hline umc1993 & 10.06 & 40 & 23 & 0 & 0.032 & Y \\
\hline
\end{tabular}

$* * \mathrm{P}<0.001$. 
In many plant species, the most commonly reported genetic factors associated with distorted segregation ratio occur at the gamete and zygote level. In maize, the most commonly reported genetic factors associated with distorted segregation ratio are gametophytic factors ( $\mathrm{ga}$; Mangelsdorf and Jones, 1926; Burnham, 1936; Jain, 1967; Neuffer et al., 1997). In maize, four of 14 SDRs detected in the linkage map of an elite hybrid (Zong x 87-1) were located in regions in which gamete genes were reported (Yan et al., 2003); only three of 18 SDRs were detected close to the locations of five known $g a$ factors (Lu et al., 2002). In the B73 x parviglumis linkage map, SDR3 was located near the gams 1 allele, SDR5 was located near the ga 7 allele, and SDR6 overlapped with the ga10 allele (Table 6; see Figure 1). In the B73 x diploperennis linkage map, SDR3 was located near the gams 1 allele, SDR6 overlapped with the gal allele, and SDR7 overlapped with the ga2 allele near the ga10 allele (see Table 6; see Figure 2). These SDRs could reasonably be attributed to the presence of $g a$ factors in the linkage group. The locations of other SDRs detected in both linkage maps in our studies nearly overlap with previously identified SDRs (Lu et al., 2002; Yan et al., 2003; see Table 6). Nevertheless, these SDRs had no correlation with the ga factors and lack a clear explanation. The results suggest that there may be other genetic reasons for segregation distortion.

\begin{tabular}{|c|c|c|c|c|c|c|c|c|}
\hline $\begin{array}{l}\text { Lu. et al. } \\
(2002)\end{array}$ & Location (bin) & $\begin{array}{l}\text { Yan et al. } \\
\text { (2003) }\end{array}$ & Location (bin) & parviglumis & Location & diploperennis & Location & $\begin{array}{l}\text { Gametophytic } \\
\text { factors location }\end{array}$ \\
\hline SDR1.1 & $1.02-1.04$ & SDR1-1 & $1.03-1.04$ & SDR1 & $1.05-1.07$ & SDR2 & 1.10 & \\
\hline SDR1.2 & $1.05-1.08$ & SDR1-2 & $1.06-1.08$ & & $1.07-1.08$ & SDR1 & $1.02-1.07$ & \\
\hline SDR1.3 & $1.09-1.11$ & & & SDR2 & 1.11 & & & \\
\hline SDR2.1 & $2.01-2.02$ & & & & & & & \\
\hline SDR2.2 & $2.03-2.05$ & & & SDR3 & $2.05-2.06$ & & & gams1 (Bin2.04) \\
\hline SDR2.3 & $2.07-2.09$ & SDR2-1 & $2.06-2.08$ & & & $\begin{array}{l}\text { SDR3 } \\
\text { SDR4 }\end{array}$ & $\begin{array}{l}2.07-2.08 \\
2.08-2.09\end{array}$ & \\
\hline SDR3.1 & $3.04-3.05$ & SDR3-1 & $3.05-3.05$ & SDR4 & $3.00-3.05$ & SDR5 & $3.02-3.06$ & \\
\hline SDR3.2 & $3.06-3.07$ & SDR3-2 & $3.05-3.05$ & SDR5 & $3.06-3.07$ & & & ga7 (Bin3.09) \\
\hline SDR4.1 & 4.02-4.05 & SDR4-1 & 4.05-4.06 & & & SDR6 & $4.01-4.08$ & ga1 (Bin4.02) \\
\hline SDR4.2 & $4.09-4.11$ & SDR4-2 & $4.05-4.06$ & & & & & \\
\hline SDR5.1 & $5.05-5.07$ & SDR5-1 & $5.03-5.04$ & SDR6 & $5.01-5.02$ & $\begin{array}{l}\text { SDR7 } \\
\text { SDR8 }\end{array}$ & $\begin{array}{l}5.03-5.05 \\
5.06-5.08\end{array}$ & $\begin{array}{l}\text { ga10 (Bin5.00-5.02) } \\
\text { ga2 (Bin5.04-5.05) }\end{array}$ \\
\hline SDR6.1 & $6.05-6.07$ & $\begin{array}{l}\text { SDR6-1 } \\
\text { SDR6-2 }\end{array}$ & $\begin{array}{l}6.01 \\
6.04-6.05\end{array}$ & SDR7 & 6.05 & & & ga*-GFS1994 (chr6) \\
\hline SDR7.1 & $7.01-7.03$ & $\begin{array}{l}\text { SDR7-1 } \\
\text { SDR7-2 }\end{array}$ & $\begin{array}{l}7.00-7.01 \\
7.02\end{array}$ & SDR8 & $\begin{array}{l}0.03 \\
7.03\end{array}$ & & & \\
\hline $\begin{array}{l}\text { SDR8.1 } \\
\text { SDR 8 ? }\end{array}$ & $\begin{array}{l}8.02-8.03 \\
805-808\end{array}$ & & & & & SDR9 & $8.01-8.03$ & \\
\hline $\begin{array}{l}\text { SDR8.2 } \\
\text { SDR9.1 }\end{array}$ & $\begin{array}{l}8.00-8.08 \\
9.01-9.04\end{array}$ & SDR9-1 & 9.02 & & & SDR 10 & 9.07 & $\begin{array}{l}\text { ga8 (Bin9.02) } \\
\text { ga*-94-764 (chr9) }\end{array}$ \\
\hline SDR10.1 & $10.02-10.04$ & SDR10-1 & $10.01-10.02$ & SDR9 & $10.01-10.03$ & $\begin{array}{l}\text { SDR11 } \\
\text { SDR12 }\end{array}$ & $\begin{array}{l}10.02-10.03 \\
10.03-10.04\end{array}$ & \\
\hline SDR 10.2 & $10.06-10.07$ & & & & & SDR13 & $10.04-10.06$ & gams2 (unknown) \\
\hline
\end{tabular}

\section{ACKNOWLEDGMENTS}

Research supported by the National Natural Science Foundation of China (\#30700472 and \#31171559) and the Ministry of Science and Technology of China (\#2006AA10Z148, \#2006AA10A107, and \#2009CB118400). 


\section{REFERENCES}

Birky CW Jr and Walsh JB (1988). Effects of linkage on rates of molecular evolution. Proc. Natl. Acad. Sci. U. S. A. 85: 6414-6418.

Bonierbale MW, Plaisted RL and Tanksley SD (1988). RFLP maps based on a common set of clones reveal modes of chromosomal evolution in potato and tomato. Genetics 120: 1095-1103.

Borts RH and Haber JE (1987). Meiotic recombination in yeast: alteration by multiple heterozygosities. Science 237: $1459-1465$.

Bregger J (1918). Linkage in maize: the C aleurone factor and waxy endosperm. Am. Nat. 52: 57-61.

Briggs WH, McMullen MD, Gaut BS and Doebley JD (2007). Advance QTL mapping in a RIL resource for positional cloning of maize domestication genes. Genetics 177: 1915-1928.

Burnham CR (1936). Differential fertilization in the Bt-Pr linkage group of maize. J. Am. Soc. Agron. 28: 968-975.

Coe EH, Hoisincton DA and Neuffer MG (1990). Linkage Map of Corn (Zea mays L.). In: Genetic Maps (O’Brienc SJ, ed.). Spring Harbor Laboratory, Cold Spring Harbor, 639-667.

Cohen JI and Galinat WC (1984). Potential use of alien germplasm for maize improvement. Crop Sci. 24: 1011-1015.

Doebley J and Stec A (1991). Genetic analysis of the morphological differences between maize and teosinte. Genetics 129: 285-295.

Doebley J and Stec A (1993). Inheritance of the morphological differences between maize and teosinte: comparison of results for two $\mathrm{F}_{2}$ populations. Genetics 134: 559-570.

Doebley J, Goodman MM and Stuber CW (1984). Isoenzymatic variation in Zea (Gramineae). Syst. Boatany 9: 203-218.

Doerge RW (2002). Mapping and analysis of quantitative trait loci in experimental populations. Nat. Rev. Genet. 3: 43-52.

Emerson RA and Beadle GW (1932). Studies of Euchlaena and its hybrids with Zea: crossing over between the chromosomes of Euchlana and those of Zea. Z. indukt Abstamm-u. VererbLehre 62: 305-315.

Gardiner JM, Coe EH, Melia-Hancock S, Hoisington DA, et al. (1993). Development of a core RFLP map in maize using an immortalized $\mathrm{F}_{2}$ population. Genetics 134: 917-930.

Harushima Y, Kurata N, Yano M, Nagamura Y, et al. (1996). Detection of segregation distortions in an indica-japonica rice cross using a high-resolution molecular map. Theor. Appl. Genet. 92: 145-150.

Jain SK (1967). Population dynamics of a gametophyte factor controlling selective fertilization. Genetica 38: 485-503.

Konishi T, Yano Y and Abe K (1992). Geographic distribution of alleles at the Ga2 locus for segregation distortion in barley. Theor. Appl. Genet. 85: 419-422.

Lander ES, Green P, Abrahamson J, Barlow A, et al. (1987). MAPMAKER: an interactive computer package for constructing primary genetic linkage maps of experimental and natural populations. Genomics 1: 174-181.

Lauter N and Doebley JD (2002). Evidence for genetic variation for phenotypically invariant traits in teosinte. Maize Genet. Newslett. 76: 54-55.

Lu H, Romero-Severson J and Bernardo R (2002). Chromosomal regions associated with segregation distortion in maize. Theor. Appl. Genet. 105: 622-628.

Mangelsdorf PC and Jones DF (1926). The expression of Mendelian factors in the gametophyte of maize. Genetics 11: 423-455.

Mano Y, Muraki M, Fujimori M, Takamizo T, et al. (2005a). AFLP-SSR maps of maize x teosinte and maize X maize: comparison of map length and segregation distortion. Plant Breed. 124: 432-439.

Mano Y, Muraki M, Fujimori M, Takamizo T, et al. (2005b). Identification of QTL controlling adventitious root formation during flooding conditions in teosinte (Zea mays ssp. huehuetenangensis) seedlings. Euphytica 142: 33-42.

Mano Y, Omori F, Takamizo T, Kindiger B, et al. (2007). QTL mapping of root aerenchyma formation in seedlings of a maize x rare teosinte "Zea nicaraguensis" cross. Plant Soil 295: 103-113.

Mano Y, Omori F, Kindiger B and Takahashi H (2008). A linkage map of maize x teosinte Zea luxurians and identification of QTLs controlling root aerenchyma formation. Mol. Breed. 21: 327-337.

Mano Y, Omori F, Loaisiga CH and Bird R McK (2009). QTL mapping of above-ground adventitious roots during flooding in maize $\mathrm{x}$ teosinte "Zea nicaraguensis" backcross population. Plant Root 3: 3-9.

Matsushita S, Iseki T, Fukuta Y, Araki E, et al. (2003). Characterization of segregation distortion on chromosome 3 induced in wide hybridization between indica and japonica type rice varieties. Euphytica 134: 27-32.

Murray MG and Thompson WF (1980). Rapid isolation of high molecular weight plant DNA. Nucleic Acids Res. 8: 43214325.

Neuffer MG, Coe EH and Wessler SR (1997). Mutants of Maize. Cold Spring Harbor Laboratory Press, Cold Spring Harbor.

Omori F and Mano Y (2007). QTL mapping of root angle in $\mathrm{F}_{2}$ populations from maize 'B73' X teosinte 'Zea luxurians'.

Genetics and Molecular Research 11 (1): 693-706 (2012)

CFUNPEC-RP www.funpecrp.com.br 
Plant Root 1: 57-65.

Paterson AH, Damon S, Hewitt JD, Zamir D, et al. (1991). Mendelian factors underlying quantitative traits in tomato: comparison across species, generations, and environments. Genetics 127: 181-197.

Pereira MG, Lee M, Bramel-Cox P, Woodman W, et al. (1994). Construction of an RFLP map in sorghum and comparative mapping in maize. Genome 37: 236-243.

Sibov ST, de Souza CLJ, Garcia AA, Garcia AF, et al. (2003). Molecular mapping in tropical maize (Zea mays L.) using microsatellite markers. 1. Map construction and localization of loci showing distorted segregation. Hereditas 139: 96-106.

Tulsieram L, Compton WA, Morris R, Thomas-Compton M, et al. (1992). Analysis of genetic recombination in maize populations using molecular markers. Theor. Appl. Genet. 84: 65-72.

Wendel JF, Edwards MD and Stuber CW (1987). Evidence for multilocus genetic control of preferential fertilisation in maize. Heredity 58: 297-301.

Westerbergh A and Doebley J (2002). Morphological traits defining species differences in wild relatives of maize are controlled by multiple quantitative trait loci. Evolution 56: 273-283.

Williams CG, Goodman MM and Stuber CW (1995). Comparative recombination distances among Zea mays L. inbreds, wide crosses and interspecific hybrids. Genetics 141: 1573-1581.

Xu Y, Zhu L, Xiao J, Huang N, et al. (1997). Chromosomal regions associated with segregation distortion of molecular markers in $\mathrm{F}_{2}$, backcross, doubled haploid, and recombinant inbred populations in rice (Oryza sativa L.). Mol. Gen. Genet. 253: 535-545.

Yan JB, Tang H, Huang YQ, Zheng YL, et al. (2003). Genetic analysis of segregation distortion of molecular markers in maize $\mathrm{F}_{2}$ population. Yi Chuan Xue Bao 30: 913-918.

Yao H and Schnable PS (2005). Cis-effects on meiotic recombination across distinct a1-sh2 intervals in a common Zea genetic background. Genetics 170: 1929-1944. 